Yu.V. Batygin, E.A. Chaplygin, O.S. Sabokar

\title{
ESTIMATING THE LIMIT POSSIBILITIES OF THE STEP CHARGING SYSTEM FOR CAPACITIVE ENERGY STORAGE
}

The aim of the article is to estimate the limit possibilities of step-by-step charging the capacitive energy storage which are caused by the achievement of a balance among the processes of the receiving and losing of electromagnetic energy. Originality. For the first time a step the charging system as a high power converter for pulsed load was considered, that allow to simplify similar charging systems and make its chipper while saving output characteristics and common quality. Methodology of the analysis applied is based on the classic electric circuits theory. All of the resulted carried out, were obtained as the differential equation solutions and its behavior was analyses analytically. Results. The basic diagram of the step-by-step charging system what is an alternative to the traditional variant with the step-up transformer was described. This system realizes the serial charge voltage increasing by the separate portions of energy, which has been, accumulated preliminary in the inductive energy storage. The formulas for estimating the limit possibilities of the step-by-step charging were got. These limits are caused by achieving a balance of the entering and losing electromagnetic energy. The applicability of the formulas was illustrated by numerical examples. Practical value. According to the results that were obtained, it is possible to note, that the step charging system is acceptable to be used as a high power converter for capacitive storage charging. References 5, figures 1 .

Key words: capacitive energy storage, step-charged system, analytical analysis, electrical circuits, inductive energy storage.

Описана принципиальная схема ступенчатого заряда емкости, альтернативной традиционному варианту с повыцающим трансформатором и предполагающей последовательное повыщение зарядного напряжения за счёт подачи отдельных порций энергии, предварительно запасённой в обмотке специального индуктивного накопителя. Получены формулы для оценки предельных возможностей ступенчатого заряда, обусловленных достижением баланса в процессах поступления и потерь электромагнитной энергии. Применимость формул проиллюстрирована численными примерами. Библ. 5, рис. 1.

Ключевые слова: емкостной накопитель энергии, система ступенчатого заряда, аналитический анализ, электрические цепи, индуктивный накопитель энергии.

Introduction, analysis of publications. The traditional scheme of the capacitor storage charge comprises two main components: a voltage step-up transformer and rectifier (Fig. 1,a). Not stopping on description of the efficiency and highly successful examples of the long exploitation of the different electrical engineering devices, it should note this scheme is not without shortcomings. Among the most significant shortcomings, the real performance cumbersome is the main (including weight and overall dimensions, electronic components, etc.) and its relatively high cost $[1,2]$.

So-called step-by-step charging systems for capacitor banks are devoid of these shortcomings. The effectiveness of this charge is based on the «portioned» pumping of the capacitive electromagnetic energy by the voltage pulses the amplitude of which increases in time [3, 4].

However, how it follows from a priori phenomenological considerations the practical possibilities of scheme with the immediate implementation of the step-by-step charging are quite limited.

According to the physical point of view the above mentioned limitations are caused by the fact when the next charging voltage pulse comes to the capacitance input a discharge is occurring simultaneously. Upon the reaching of a balance between the incoming electromagnetic energy level and the level of its loss the charging process must stop, and the amplitude of the voltage on the capacitance (as well as the stored energy!) should be remained unchanged.

The aim of the article is estimating the limit possibilities of step-by-step charging the capacitive energy storage which are caused by the achievement of a balance among the processes of the receiving and losing of electromagnetic energy.

The calculated relationships, the numerical estimates. At the beginning a brief description of the step-bystep charging scheme for the capacitor energy storage which was adopted as a calculation model and was shown at the Fig. $1, b$ will be given.

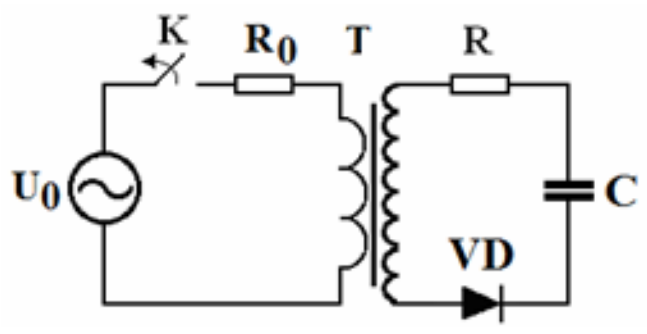

$a$

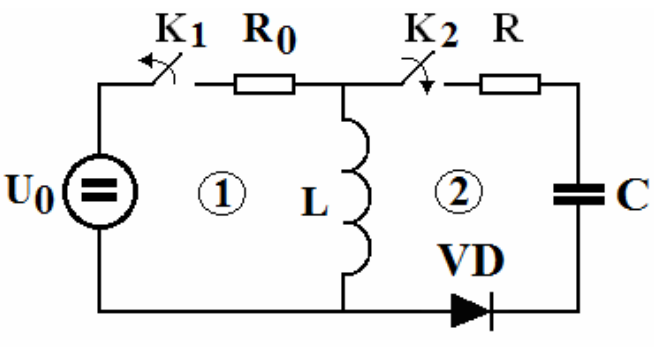

$b$

Fig. 1. The schematics charging of the capacitive energy storage: $a$-it is the traditional variant with the step-up charging transformer $T ; b-$ it is a variant without a step-up charging transformer

(C) Yu.V. Batygin, E.A. Chaplygin, O.S. Sabokar 
This scheme consists of 2 major blocks: 1 - inductance $L$ (a block of energy charging) which could be presented by DC or rectified voltage source with an amplitude $U_{0}$ and $2-$ a block which transforms a pre-stored magnetic energy into electrical energy capacitor storage $C$ ( $R_{0}$ and $R$ - are current-limiting resistors).

Initially, the switch $K_{1}$ is closed, $K_{2}-$ open. Through the resistor $R_{0}$ the signal from the voltage source $U_{0}$ enters in the loop circuit 1 and charges the inductive storage $L$.

Upon reaching the maximum accumulated magnetic energy the key $K_{1}$ is being opened and the key $K_{2}$ is being closed. The transformation of inductance energy $L$ into capacitive energy $C$ is occurring. The capacitor is being charged up to some voltage level that is equal to the sum of the initial value and of some increment.

At the end of the charge switch $K_{2}$ is opened and the switch $K_{1}$ is closed. The circuit takes up the initial state and the above described process is being repeated.

In solving the problem according to the formulated aim the mathematical apparatus of the electrical circuit theory was used [5].

Leaving out the details of integrating the differential equation which describes the transition process in the circuit blocks 1 and the necessary mathematical transformations the final expression for the current in the inductor can be wrote.

$$
J(t)=\frac{U_{0}}{R_{0}} \cdot\left(1-e^{-\frac{t}{\tau_{0}}}\right)
$$

where $\tau_{0}=L / R_{0}$ - is the time constant of the $\left\langle R_{0}-L »\right.$ circuit.

After time to $t \geq 3 \cdot \tau_{0}$ in accordance with (1) $J(t) \rightarrow J_{m}=U_{0} / R_{0}$. It means the current and the electromagnetic energy are achieving their maximum.

Further, in accordance with the description of the processes in the step-by-step charging scheme in Fig. 1 the charge of the capacitor storage $C$ is occurring.

Similarly to the above the details integrating of the equation of the transition process in the circuit 2 (for open $K_{1}$ and closed $K_{2}$ ) were omitted, and the final expression for the voltage on the capacitance $U_{\mathrm{C}}(t)$ was written.

$$
\begin{aligned}
& U_{C}(t)=e^{-\delta t}\left[\left(\left(\frac{J_{m}}{\omega C}\right)+\frac{\delta}{\omega} \cdot U_{C 0}\right) \cdot \sin (\omega t)+\right. \\
& \left.+U_{C 0} \cdot \cos (\omega t)\right],
\end{aligned}
$$

where $\delta=R / 2 L-$ is the damping rate; $\omega=\sqrt{\omega_{0}^{2}-\delta^{2}}-$ is the oscillation frequency; $\omega_{0}=\frac{1}{\sqrt{L C}}$ - is the own circuit frequency; $U_{C 0}$ - is the initial capacitance voltage; $J_{m}=U_{0} / R_{0}-$ is the inductor current at the moment of commutation.

The maximum increment of voltage in the arbitrary cycle relatively to the initial value takes place after time equaled to a quarter of the oscillation period $-\omega \cdot t=\pi / 2$

$$
\begin{aligned}
& \Delta U_{C}(t)=U_{C}\left(t=\frac{\pi}{2 \omega}\right)-U_{C 0}= \\
& =e^{-\delta_{0} \cdot \frac{\pi}{2}}\left[\left(\left(\frac{J_{m}}{\omega C}\right)+\delta_{0} \cdot U_{C 0}\right)-U_{C 0}\right],
\end{aligned}
$$

where $\delta_{0}=\delta / \omega-$ is the relative damping rate.

Charging time what is equaled to the quarter of the period is conditioned by the diode presence in the circuit 2 .

Accepting the idealization when $\delta_{0} \rightarrow 0$ which relates to the maximum possible values of the output parameters of the charge with the lowest possible energy dissipation in the active resistance of the circuit according to the dependence (3) we get

$$
\lim _{\delta_{0} \rightarrow 0} \Delta U_{C}\left(t=\frac{\pi}{2 \omega}\right) \approx U_{0} \cdot\left(\frac{Z}{R_{0}}\right)-U_{C_{0}},
$$

where $N=\frac{U_{C 0}}{U_{0}} \approx \frac{Z}{R_{0}}=\frac{1}{R_{0}} \cdot \sqrt{\frac{L}{C}}$ is the circuit wave resistance.

It is clear the condition of the balance in the process of income and loss of electromagnetic energy is equaled to zero growth in the next charging cycle, that is $\lim _{\delta_{0} \rightarrow 0} \Delta U_{C}\left(t=\frac{\pi}{2 \omega}\right) \rightarrow 0$. If to take into account that the initial value of the voltage on the capacitance in the same charging cycle is the result of accumulation process starting with the voltage of the external source $U_{0}$ during the previous cycles it is possible to write $U_{\mathrm{C} 0}=N U_{0}$.

According to the remarks above, with help of the relation (4), we find that

$$
N=\frac{U_{C 0}}{U_{0}} \approx \frac{Z}{R_{0}}=\frac{1}{R_{0}} \cdot \sqrt{\frac{L}{C}} .
$$

The dependence (5) is the solution of the formulated aim. It fixes the limiting number of the possible cycles of the capacitor storage charge to achieve the maximum voltage value, which is the highest for the given parameters of the system.

\section{Numerical estimates.}

Let us, it is necessary to charge the capacitive energy storage $C=1200 \mu \mathrm{F}$ of the magnetic pulse plant up to $U_{\mathrm{C} 0}=2.2 \mathrm{kV}$ by the AC source $U_{0}=220 \mathrm{~V}$. An active circuit resistance of the branch with the magnetic energy inductive storage is $R_{0}=0.1 \mathrm{Ohm}$. [1].

It is necessary to find the next data:

- the required quantity of charging cycles $\mathrm{N}$;

- the value of inductance that ensures the implementation of the step-by-step charging process $L$;

- the maximum charge current of the inductive storage $J_{m}$

- time of achievement of the maximum inductor current $t_{\mathrm{L}}$.

From (5) we find the required number of charge cycles:

$$
N=\frac{U_{C 0}}{U_{0}}=\frac{2200}{220}=10 .
$$

The value of inductance that ensures the implementation of the step-by-step charging process is also determined by (5)

$$
L=\left(N \cdot R_{0}\right)^{2} \cdot C=(10 \cdot 0.1)^{2} \cdot 1200 \cdot 10^{-6}=0.0012 \text { H. (7) }
$$

The maximum charging current of the inductive storage is based on (1), 


$$
J_{m}=\frac{U_{0}}{R_{0}}=\frac{220}{0.1}=2.2 \mathrm{kA} .
$$

The necessary time term to reach the maximum current at the inductive storage could be find as (formula (1))

$$
t \geq 3 \cdot \frac{L}{R_{0}}=3 \cdot \frac{0.0012}{0.1}=0.036 \mathrm{~s} .
$$

Thus, the charge up of capacity $C=1200 \mu \mathrm{F}$ up to $2.2 \mathrm{kV}$ with mains voltage equaled to $\sim 220 \mathrm{~V}$ can be carried out during 10 cycles of the step-by-step charge, with a maximum charging current in the inductance circuit $\sim 2.2 \mathrm{kA}$. The necessary voltage level could be achieved in $\sim 0.036 \mathrm{~s}$.

\section{Conclusions.}

1. The work and benefits of the capacitance step-bystep charging system which is a successful alternative to the traditional scheme with step-up transformer and based on the portioned energy charge was described.

2. The estimation of limit possibilities of the step-bystep charging for the capacitive energy storage which are caused by achievement of balance among the processes of receiving and losing the electromagnetic energy was fulfilled.

3. The simple calculated ratios were received. Their applicability was illustrated by some numerical examples.

\section{REFERENCES}

1. Batygin Yu.V., Lavinskiy V.I., Khimenko L.T. Impul'snyye magnitnyye polya dlya progressivnykh tekhnologiy. Tom 1. Izdaniye vtoroye, pererabotannoye i dopolnennoye. [Pulsed magnetic fields for advanced technologies. Vol.1. 2nd edition, revised and enlarged.] Kharkov, MOST-Tornado Publ., 2003. 284 p. (Rus).

2. Orlov B.D., Dmitriyev Yu.V., Chakalev A.A., Sidyakin V.A., Marchenko A.L. Tekhnologiya i oborudovaniye kontaktnoy svarki [Technology and equipment for the contact welding]. Moscow, Mechanical Engineering Publ., 1975. 536 p. (Rus).

3. John D. Lenk. Simplified Design of Switching Power Supplies. Elsevier Publishing House, 1996. 235 p. Electronic ISBN: 9780080517209.

4. Marasco K. How to Apply DC-to-DC Step-Up (Boost) Regulators. Analog Devices. AN-1132 Application Note: 2011. Available at: http://www.analog.com/media/ru/technicaldocumentation/application-notes/AN-1132.pdf (accessed 22 May 2012).

5. Atabekov G.I. Osnovy teorii tsepei [The base of the circuits theory]. Moscow. Energy Publ., 1969. 427 p. (Rus).

Yu.V. Batygin ${ }^{1}$, Doctor of Technical Science, Professor,

E.A. Chaplygin ${ }^{1}$, Candidate of Technical Science, Associate

Professor,

O.S. Sabokar ${ }^{1}$,

${ }^{1}$ Kharkov National Automobile and Highway University,

25, Petrovskogo Str., Kharkov, 61002, Ukraine.

phone+38057 7073727, e-mail: batygin48@mail.ru,

chaplygin.e.a@gmail.com,o.s.sabokar@gmail.com

How to cite this article:

Batygin Yu.V., Chaplygin E.A., Sabokar O.S. Estimating the limit possibilities of the step charging system for capacitive energy storage. Electrical engineering \& electromechanics, 2016, no.2, pp. 35-37. doi: 10.20998/2074272X.2016.2.06. 